\title{
Characterisation of a MQW electroabsorption modulator as an all-optical demultiplexer
}

Oxenløwe, Leif Katsuo; Romstad, Francis Pascal; Tersigni, Andrea; Højfeldt, Sune; Yvind, Kresten; Skovgaard, Peter M. W.; Hoppe, Karsten; Hanberg, J.

Published in:

Proceedings on The 14th Annual Meeting of the IEEE Lasers and Electro-Optics Society

Link to article, DOI:

10.1109/LEOS.2001.969160

Publication date:

2001

Document Version

Publisher's PDF, also known as Version of record

Link back to DTU Orbit

Citation (APA):

Oxenløwe, L. K., Romstad, F. P., Tersigni, A., Højfeldt, S., Yvind, K., Skovgaard, P. M. W., Hoppe, K., \& Hanberg, J. (2001). Characterisation of a MQW electroabsorption modulator as an all-optical demultiplexer. In Proceedings on The 14th Annual Meeting of the IEEE Lasers and Electro-Optics Society (Vol. 1, pp. 36-37) https://doi.org/10.1109/LEOS.2001.969160

\section{General rights}

Copyright and moral rights for the publications made accessible in the public portal are retained by the authors and/or other copyright owners and it is a condition of accessing publications that users recognise and abide by the legal requirements associated with these rights.

- Users may download and print one copy of any publication from the public portal for the purpose of private study or research.

- You may not further distribute the material or use it for any profit-making activity or commercial gain

- You may freely distribute the URL identifying the publication in the public portal 
ME2

$1: 45 \mathrm{pm}-2: 00 \mathrm{pm}$

\title{
Characterisation of a MQW Electroabsorption Modulator as an All-optical Demultiplexer
}

\author{
L.K. Oxenløwe(1), F. Romstad(1), A. Tersigni(1), S. Højfeldt(1), K. Yvind(1), P.M.W. \\ Skovgaard (2), K. Hoppe(3), J. Hanberg(3)
}

(1) COM, Technical University of Denmark, Building 345V, DK-2800 Kgs. Lyngby, Denmark

(lo@com.dtu.dk)

(2) Now with Crystal Fibre A/S, Birkerød Denmark

(3) GiGA-Intel, Denmark

\section{Introduction}

The electroabsorption modulator (EAM) is a very versatile component and has been shown to enable several different functionalities. The EAM was for instance recently demonstrated as the central component in a $160 \mathrm{~Gb} / \mathrm{s}$ transmitter and a $160 \mathrm{~Gb} / \mathrm{s}$ receiver [1], where the EAM was controlled electrically. Controlling the EAM optically has also been the focus of much attention recently, and functionalities demonstrated so far include wavelength conversion and regeneration at $40 \mathrm{~Gb} / \mathrm{s}$ using crossabsorption modulation (XAM) [2], clock recovery and simultaneous demultiplexing at $20 \mathrm{~Gb} / \mathrm{s}$ using XAM [3], and wavelength conversion at $40 \mathrm{~Gb} / \mathrm{s}$ using XPM [4]. In [5] we demonstrated 80 to $10 \mathrm{~Gb} / \mathrm{s}$ all-optical demultiplexing in a single EAM using saturable absorption. The result is shown in figure 1 . Demultiplexing from such high bit rates was not possible when modulating the

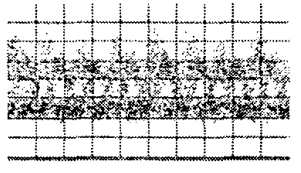

In $(80 \mathrm{~Gb} / \mathrm{s})$

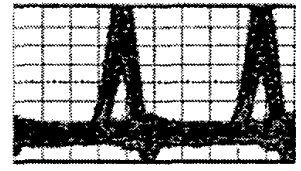

Out $(10 \mathrm{~Gb} / \mathrm{s})$
Figure 1: 80/10 Gb/s demultiplexed eye [5]

component electrically. In this paper we present a detailed investigation of the optical switching performance of an EAM. As a result, it is found that $100 / 10 \mathrm{~Gb} / \mathrm{s}$ demultiplexing should be possible.

\section{Basic Principle - Saturable Absorption}

The EAM used here is a multi quantum well (MQW) InGaAsP device with 10 wells each $10 \mathrm{~nm}$ wide. By applying an external voltage to the EAM the absorption edge is shifted towards higher wavelengths through the quantum confined Stark effect (QCSE). Hence, wavelengths previously free to propagate through the EAM are absorbed. Injecting a high power optical pump into the EAM can then bleach this electrically induced absorption. This absorption saturation is due to a combination of bandfilling in the quantum wells, and a reduction of the external field in the active region caused by the screening due to photo-generated carriers [6]. The persistence of this absorption saturation depends on how fast the photogenerated carriers can be swept out of the active region of the EAM, and this depends on the applied reverse bias. Hence the pump pulse opens a transmission window for the otherwise absorbed probe (data), and the reverse bias closes the window again.

The set-up used for characterising the EAM is shown in figure 2 . The set-up requires only one pulse source (a mode-locked fibre ring laser (ML-FRL), $\lambda_{\mathrm{FRL}}=1553 \mathrm{~nm}$, pulse width $2 \mathrm{ps,}$, repetition rate $10 \mathrm{GHz}$ ).

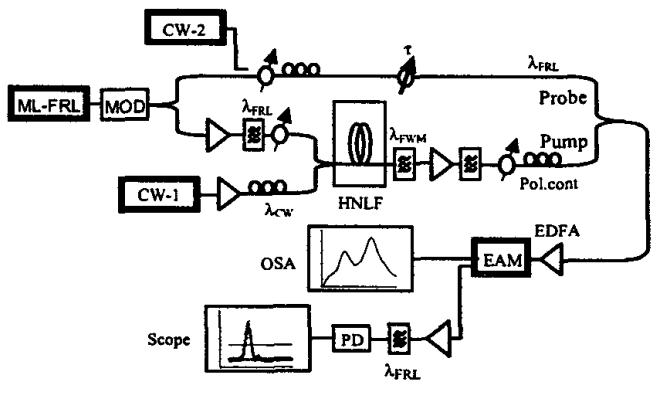

Figure 2: Schematic set-up for pump-probe measurements

The pulses are sent through a $\mathrm{LiNbO}_{3} \mathrm{MZ}$ data modulator (MOD), which imposes a programmable bit sequence on the $10 \mathrm{GHz}$ pulse stream. This allows for the tailoring of various repetition rates and, since the average output power of the EDFAs is approximately constant, the acquired pulse energy can be varied. After the modulator the pulse train is split into a probe arm and a pump arm. In order to make non-degenerate XAM, the wavelength is shifted in the pump arm by four wave mixing (FWM) in $500 \mathrm{~m}$ of highly non-linear fibre (HNLF) [7]. The ML-FRL pulses and a $\mathrm{CW}$ beam at $1559 \mathrm{~nm}$ from the CW-1 tunable laser source enter the HNLF, and a partly degenerated FWM process takes place, generating new optical frequencies $\left(\lambda_{\mathrm{FWM}}=\right.$ $\left.\left(2 / \lambda_{\text {FRL }}-1 / \lambda_{\text {cW-1 }}\right)^{-1}\right)$ [8]. The pulse replica of the ML-FRL pulse at the new wavelength $\lambda_{\mathrm{FWM}}(1547 \mathrm{~nm})$ is filtered and amplified, and used as the pump for the EAM. FWM is an almost instantaneous process, and hence the generated pulses at $\lambda_{\text {Fu }}$ will be nearly as short as the original ones. After amplification and filtering, the pulses that arrive at the EAM, both from the ML-FRL and from the HNLF, are around $2.8 \mathrm{ps}$ wide. The probe arm contains a variable time delay, so that the probe pulses can be scanned across the switching window opened by the pump pulse. The transmitted probe is detected in an optical spectrum analyser (OSA), with a very high sensitivity. One can also use a $\mathrm{CW}$ probe $(\mathrm{CW}-2)$, and monitor the transmission on a 
sampling oscilloscope (Scope). This approach is very useful when optimising the absorption saturation, but is limited by the $15 \mathrm{~dB}$ amplitude resolution and the roughly 15 ps pulse width resolution of the scope.

Using the pulsed probe and the OSA hence greatly improves the temporal $(2.8 \mathrm{ps})$ and the amplitude $(\sim 100$ $\mathrm{dB})$ resolution, and due to the modulator, very high pump pulse energies can be obtained.

\section{Switching Windows}

Figure 3 shows the scope trace together with the measured window obtained with a pulsed probe. The pump pulse energy is around $110 \mathrm{pJ}$, the reverse bias is $-10 \mathrm{~V}$, the probe pulse energy is about $2 \mathrm{pJ}$, and the time delay takes steps of $3.5 \mathrm{ps}$.
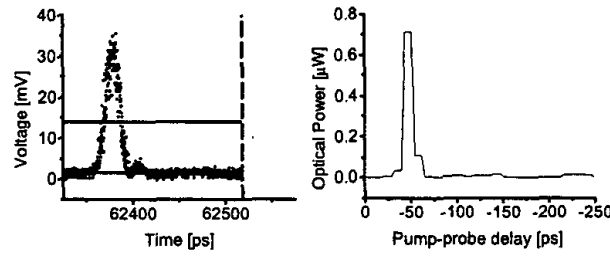

Figure 3: Switching windows measured on scope (left), and using the OSA (right) with improved resolution.

The scope trace shows a very narrow pulse with a clear ringing at the trailing edge of the pulse. This is due to the limited time resolution of the scope, and hence the real width of the switching window is less.than the 15 ps suggested by the scope trace. The amplitude is about 15 $\mathrm{dB}$, and is hence also at the limit of the scope

The pump-probe trace is shown in figure 3 (right), and reveals a $25 \mathrm{~dB}$ extinction ratio (ER) and a FWHM of 11 ps. The high ER and the narrow width revealed in this measurement really demonstrate the superiority of this measurement to the scope measurement. The result is reproducible (within a few $\mathrm{dB}$ in $\mathrm{ER}$ ) and shows that with sufficient pump power and sufficient reverse bias, alloptical demultiplexing of very high bit rates is expected to be possible.

We notice that the design of an EAM for all-optical rather than electrical modulation differs in many ways, e.g. in the external bias circuit as well as in the EPI structure.

\section{Power and Bias Dependence}

The ER and the FWHM of the switching windows are investigated as a function of the applied reverse bias and the supplied pump pulse energy. Figure 4 (left) shows the results in the case of a fixed pump of $115 \mathrm{pJ}$, a fixed probe of $2 \mathrm{pJ}$ and a varying reverse bias. The FWHM drastically decreases between -3 and $-4 \mathrm{~V}$ from more than $30 \mathrm{ps}$ to around 20 ps. This decrease in FWHM is due to a faster sweep-out of photo-generated carriers. As the bias is further increased the exponential recovery becomes faster, and the FWHM is already as short as 12 ps at $-6 \mathrm{~V}$. In this series of measurements, a FWHM as narrow as 10 ps was obtained at $-9 \mathrm{~V}$. At the same time, the ER increases, since higher reverse bias gives more absorption, which can then in turn be saturated. An ER as high as $22 \mathrm{~dB}$ was obtained in this series of measurements.

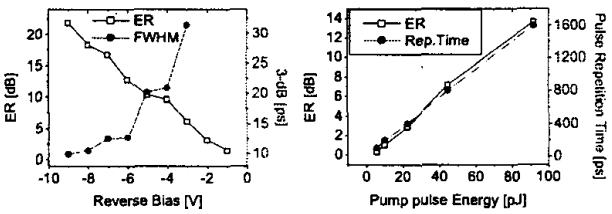

Figure 4: Switching window dependence on bias and pump power. Left: ER and FWHM as function of bias. Right: ER as function of pump pulse energy and pulse repetition time.

Figure 4 (right) shows the ER as a function of the pump energy. It is quite evident that more pump energy gives a higher contrast. Since the successive pulses must share the average gain available in the EDFA, higher bit-rates will have less energy in the pulses, and hence one would expect the ER to decrease at higher rates. This is indeed demonstrated in figure 4 (right), where the pulse separation time is also shown, together with the corresponding pulse energy and ER. This clearly explains the results of [5], stating that a $10 \mathrm{~Gb} / \mathrm{s} \quad(\sim 200$ ps pulse separation) wavelength conversion experiment gives an improvement in receiver sensitivity, whereas a $10 \mathrm{GHz}$ pump $(\sim 100$ ps pulse separation) in a demultiplexing experiment gives a small penalty. In this series of measurements, the ER only went up to $14 \mathrm{~dB}$, but the power dependence is clearly revealed. It seems very probable that the limiting factor in wavelength conversion in an EAM is the power availability at higher bit-rates. Hence, with the very narrow switching windows revealed here, it is expected to be possible to demultiplex error-freely from $80 \mathrm{~Gb} / \mathrm{s}$ and even from 100 $\mathrm{Gb} / \mathrm{s}$ to $10 \mathrm{~Gb} / \mathrm{s}$, if the sufficient amount of power can be generated.

\section{Conclusion}

A detailed experimental investigation of the all-optical switching properties of an EAM has been performed. Using high pump pulse energies and high reverse bias settings, switching windows were demonstrated with ERs up to 25 $\mathrm{dB}$ and widths down to $10 \mathrm{ps}$, possibly facilitating $100 / 10$ $\mathrm{Gb} / \mathrm{s}$ demultiplexing.

\section{References}

/1/ B. Mikkelsen et al., ECOC 2000, paper 6.1.1., 2000

/2/ T. Otani et al., OFC'2000, ThP3-1, pp.226-228, 2000

13/ K. Shimomura et al., ECOC 2000, paper 9.4.5, 2000

14/ K. Nishimura et al., OFC'2001, WK5-1, 2001

15/ L.K. Oxenløwe et al., accepted for ECOC 2001

/6/ S. Højfeldt et al., CLEO 2000, paper CWK70, 2000

/7/ A.T. Clausen et al., Photon. Technol. Lett., Vol. 13, No. 1, pp 70-72, 2001

18/ P.M. Hedekvist et al., J. Lightwave Technol., Vol. 15 , No. 11, pp 2051-2058, 1997 